\title{
Electrochemical Chelation of Lead by NDA Modified Carbon Paste Electrode
}

\section{Sakina Touzara, Rachida Najih and Abdelilah Chtaini*}

Electrochemistry Laboratory of Molecular and Inorganic Materials, University Sultan Moulay Slimane, Faculty of Science and Technology, Beni Mellal, Morocco

\begin{abstract}
The analytical performance of developed DNA film screen printed biosensors designed for the detection of metals was evaluated. The modified surface exhibited an affinity to chelating metal ions in solution, forming complexes. Square wave voltammetry combined with a pre-concentrating process and standard additions were employed for trace analysis. Finally, cyclic voltammetry technique was used to characterize the developed DNA film surface behavior in presence of heavy metal.
\end{abstract}

Keywords: DNA; Modified electrode; Biosensor; SQW; Cyclic voltammetry

\section{Introduction}

A biosensor is defined by the international Union of Pure and Applied chemistry (IUPAC) as a self-contained integrated device that is capable of providing specific quantitative or semi-quantitative analytical information using a biological recognification element (bio chemical receptor), which is retained in contact direct spatial with a transduction element [1].

The DNA-based biosensor is a system that incorporates immobilized DNA as molecular recognition element in the biological active layer on the surface, and measures specific binding processes with DNA mainly using electrochemical, optical and piezoelectric transducers. The fact that the DNA sequences are unique to each organism means that any self-replicating biological organism can be distinguished. The DNA-based biosensor is also a complementary tool for the study of biomolecular interaction mechanisms of compounds with DNA, enabling the screening and evaluation of the effect caused to DNA by health hazardous compounds and oxidizing substances. There are hundreds of compounds which bind and interact with DNA, such as toxic organic molecules or heavy metals. Exposure to toxic chemicals is the cause of many human cancers; these carcinogens act by chemically damaging the DNA. Thus it is very important to explain the factors that determine affinity and selectivity in binding molecules to DNA, identify these chemicals and plan to minimize the impact of human exposure to these products.

Electrochemical techniques have the advantage in DNA biosensor design of having a rapid response time, being quantitative, sensitive, suitable for automation, cost effective, disposable, enabling in situ generation of reactive intermediates and detection of DNA damage and solving analytical problems in a wide range of contexts in order to be commercially viable. Comprehensive descriptions of research on DNA and DNA sensing [2-10] show the great possibilities of using electrochemical transduction in DNA diagnostics.

Carbon paste electrodes chemically modified are endowed with many good qualities, such as ease of handling and applicability to anodic oxidations [11]. Different modifiers for carbon paste have been reported in the last years for the electrochemical stripping analysis of heavy metals.

Recently, methods involving radical-based mechanisms have been developed for the modification of carbon surfaces with covalently attached layers of organic species. The deposition of mono or multilayers at the carbon paste surfaces serves the purpose of electrode.
Functionalization for analytical purposes, like electro analysis of heavy metals $[12,13]$.

The aim of this investigation is to highlight the potential for using DNA systems for the fabrication of electrochemical biosensors. The prepared electrodes were used for the chemical preconcentration of different heavy metals at trace levels. The DNA modified carbon paste electrode (DNA-CPE) can preconcentrate heavy metals from aqueous solution to the surface of the modified CPE by forming complexes with these ions and greatly increasing the sensitivity of its determination. The experimental data show that some of the DNA-CPEs have high sensitivity, adequate selectivity and reproducibility, and a wide operative linear range of concentrations for the determination of heavy metals in water samples. The DNA-CPEs have the advantages of simple methods of synthesis and purification and their low solubility in water.

\section{Experimental}

\section{Reagents and chemicals}

All chemicals were of the highest quality. Graphite powder (spectroscopic grade RWB, Ringsdorff-Werke GmbH, Bonn-Bad Godesberg, Germany) was obtained from Aldrich and was used without further purification. PbSO4 was obtained from Merck chemicals. Deionised water was used to prepare all solution. DNA systems were extracted from plants.

\section{Apparatus}

Electrochemical experiments were performed using a voltalab potentiostat (model PGSTAT 100, Eco Chemie B. V., Utrecht, The Netherlands) driven by the general purpose electrochemical systems data processing software (voltalab master 4 software).

All the electrochemical experiments were performed in a standard one-compartment three-electrode cell. The reference electrode was

\footnotetext{
*Corresponding author: Abdelilah Chtaini, Electrochemistry Laboratory of Molecular and Inorganic Materials, University Sultan Moulay Slimane, Faculty of Science and Technology, Beni Mellal, Morocco, Tel: +212 661-118521; E-mail: a.chtaini@usms.ma

Received August 03, 2015; Accepted August 18, 2015; Published September 01,2015

Citation: Touzara S, Najih R, Chtaini A (2015) Electrochemical Chelation of Lead by NDA Modified Carbon Paste Electrode. J Biosens Bioelectron 6: 177 doi:10.4172/2155-6210.1000177

Copyright: ( 2015 Touzara S, et al. This is an open-access article distributed under the terms of the Creative Commons Attribution License, which permits unrestricted use, distribution, and reproduction in any medium, provided the original author and source are credited.
} 
SCE and the counter electrode was platinum. All electrode potentials were referred to this reference electrode. The working electrode was DNA-CPE.

\section{Electrode preparation}

The carbon paste unmodified was prepared by adding paraffin oil to carbon powder. DNA-modified carbon paste electrodes (DNACPEs) were prepared by immobilizing the DNA system by soaking the preformed carbon paste electrode in a solution containing the DNA solution. The effect of the contact time of the CPE electrode with the DNA solution was studied.

\section{Results}

\section{Cyclic voltammetric (CV) experiments}

Preliminary CV experiments were performed to study the behavior at carbon paste electrode (CPE) and DNA-CPE.

The electrodes were first immersed in an electrochemical cell containing buffer solution (pH 7.2). Comparing CPE and DNA-CPE voltammograms (Figure 1), we find that the shape has changed which corresponds to a change of the surface morphology.

The electrochemical behavior with DNA-CPE prepared at low contact times illustrates the great difficulty for the transition electrons from the electrode surface. Cyclic voltammogram obtained with a carbon paste electrode did not show any redox peak. The deposit of the DNA onto CPE surface requires about 48 hours (Figure 1). The developed DNA films modified carbon paste electrodes were soaked, respectively, in solutions containing different concentrations of studied heavy metals for about 10 minutes, removed, then rinsed with pure water. The electrodes were then, respectively, transferred into the electrochemical cell only containing supporting electrolyte solution for cyclic voltammetry and square wave voltammetry. Figure 2 shows $\mathrm{CV}$ s for $\mathrm{Pb}$ (II) solutions obtained at different CPE modified with DNA system. The cathodic scan produces the reduced species of lead, which is deposited on the electrode. This deposition favors the oxidation process and hence the current peak of this signal (i.e., the anodic peak). The peak current is more important in the case of DNA-CPE electrode prepared with a contact time of $24 \mathrm{~h}$. the oxidation peak of lead, complexed with DNA film and CPE surface, in the cathodic scan varies as follows:

DNA-CPE cont. time $48 \mathrm{~h} \leq \mathrm{DNA}-\mathrm{CPE}$ cont. time $5 \mathrm{~h} \leq \mathrm{CPE} \leq$ DNA-CPE cont. time $24 \mathrm{~h}$

This finding allows us to show that the amount of DNA deposited in 24 hours is more important than the other electrodes (Figure 2).

The study of chelation of lead with DNA system was performed by square wave voltammetry (SQWV); however, the behavior of complexation was also studied by CV in order to understand the affinity of DNA system towards lead. The SQW voltammetry has the advantage of increasing the sensitivity of an electrode by the cancellation of the capacitive term of the overall value of the current density. The SQWV's recorded at carbon paste electrodes modified with DNA system, after exposure, $10 \mathrm{~min}$, to lead solution, in stirred solutions, are shown in Figure 3. The current densities for the oxidation of lead at the study electrodes varies prepared as follows:

DNA-CPE cont. time $24 \mathrm{~h} \approx$ DNA-CPE cont time $18 \mathrm{~h} \geq \mathrm{DNA}-\mathrm{CPE}$ cont. time $5 \mathrm{~h} \geq \mathrm{CPE}$

From these findings we can draw the following conclusions:
1. The deposition of DNA on the carbon paste electrode surface improves its sensitivity;

2. The contact time is crucial in the process of filing the DNA.

Figure 4 show the SQWVs curves recorded in buffer solution containing different concentrations of lead, at DNA-CPE electrode (contact time $24 \mathrm{~h}$ ). The peak current increases linearly with the concentration of $\mathrm{Pb}$ (II) (Figure 5).

The calculated standard deviation was used in the determination of the detection limit $(\mathrm{DL}, 3 \times \mathrm{Std})$ and the quantification limit $(\mathrm{QL}, 10 \times$ Std). From these values, the detection was $1.23 .10-5 \mathrm{~mol} / \mathrm{L}$. This value remains correct compared to that found with a CPE electrode modified by organic molecules [14].

The Figure 6 shows the optical microscopic images, recorded respectively, for CPE (a) and DNA-CPE (b) electrode. We note that the DNA film forms a thin layer that covers the all carbon surface.

\section{Conclusion}

In conclusion, it was possible demonstrating the potentiality of the proposed electrodes for chelating heavy metals. Such a biosensor is characterized by a higher sensitivity and reproducibility than those of the unmodified carbon paste electrode. Electrochemical research on DNA is of great relevance to explain many biological mechanisms. The DNA-modified electrode is a very good model for simulating the

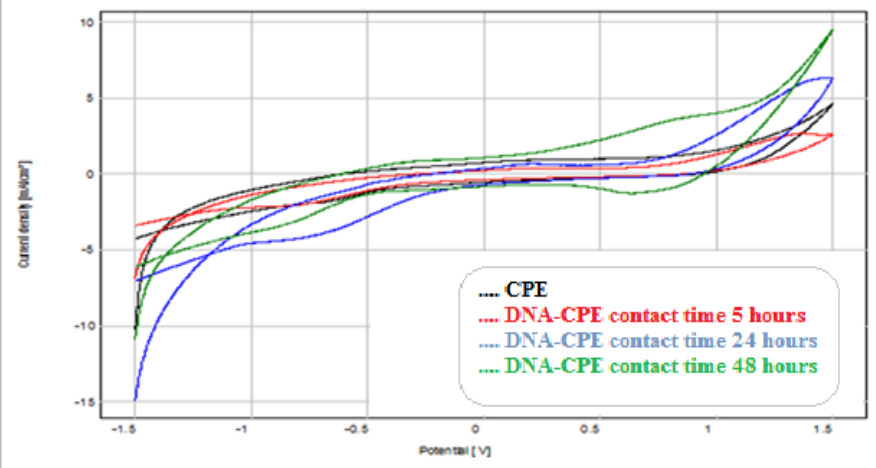

Figure 1: Cyclic voltammograms recorded in buffer solution $(\mathrm{pH} 7.2)$, at $\mathrm{CPE}$ and DNA-CPE, scan rate $100 \mathrm{mV} / \mathrm{s}$

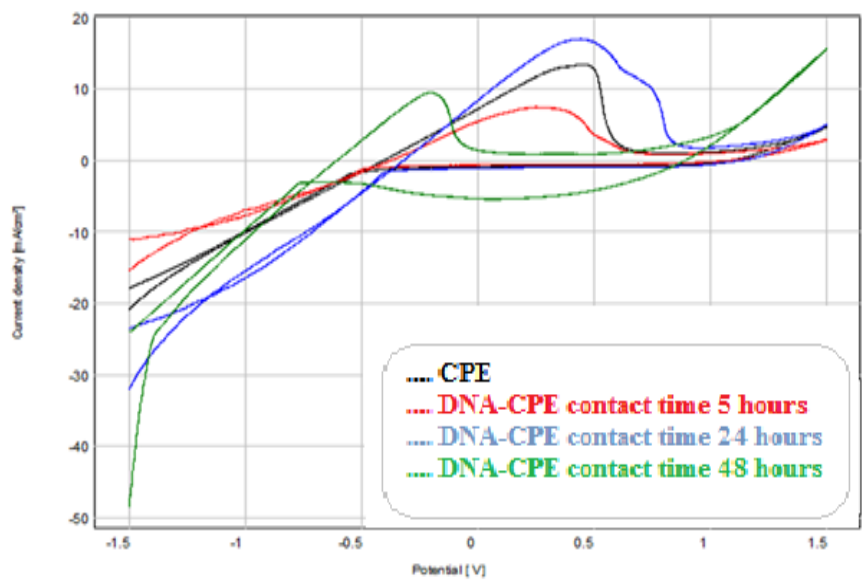

Figure 2: Cyclic voltammograms obtained by DNA-CPE and CPE electrodes at 100. $\mathrm{mV} / \mathrm{s}$, in buffer solution containing $\mathrm{Pb}^{2+}$. 
Citation: Touzara S, Najih R, Chtaini A (2015) Electrochemical Chelation of Lead by NDA Modified Carbon Paste Electrode. J Biosens Bioelectron 6: 177. doi:10.4172/2155-6210.1000177

Page 3 of 3

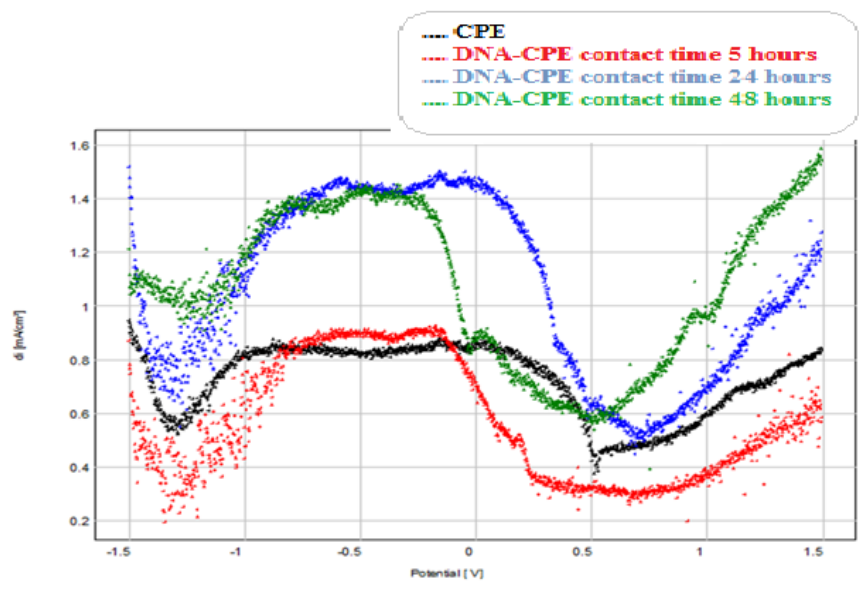

Figure 3: SQW voltammograms of different prepared electrodes in buffer solution containing lead.

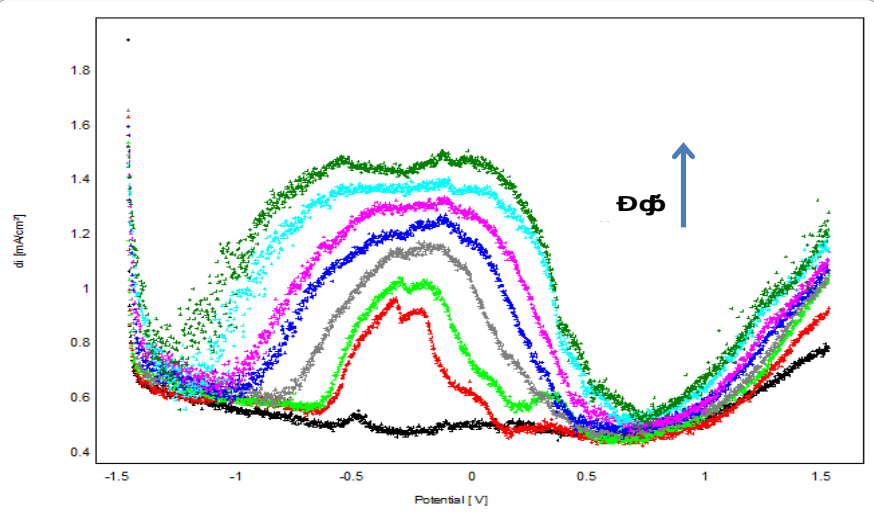

Figure 4: SQW voltammograms recorded at DNA-CPE, in buffer solution containing different concentration of lead.

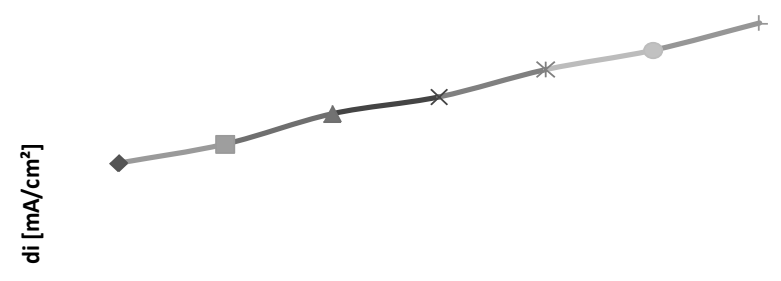

$\left[\mathrm{Pb}^{2+}\right] \mathrm{g} / \mathrm{L}$

Figure 5: Plot of peaks area versus added concentration of $\mathrm{Pb}(\mathrm{II})$
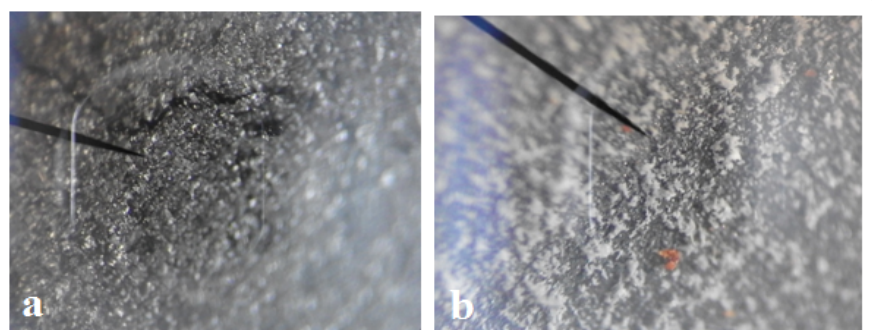

Figure 6: Optical microscopic image corresponding to a- CPE and b- DNA-CPE. nucleic acid interaction with cell membranes, potential environmental carcinogenic compounds and to clarify the mechanisms of action of drugs used as heavy metals.

\section{References}

1. Theâvenot, Toth K, Durst RA, Wilson GS (1999) Wilson, Electrochemical Biosensors: Recommended Definitions and Classification. Appl Chem 71: 2333-2348.

2. Palecek E (2002) Past, present and future of nucleic acids electrochemistry. Talanta 56: 809-819.

3. Mikkelsen SR (1996) Electrochecmical biosensors for DNA sequence detection Electroanalysis 8: 15-19.

4. Wang J, Rivas G, Cai X, Palecek E, Nielsen P, et al. (1997) DNA electrochemical biosensors for environmental monitoring. A review. Anal Chim Acta 347: 1-8.

5. Wang J, Cai X, Rivas G, Shiraishi H, Dontha N (1997) Nucleic-acid immobilization, recognition and detection at chronopotentiometric DNA chips. Biosens Bioelectron 12: 587-599.

6. Palecek E, Fojta M, Jelen F, Vetterl V (2002) Bioelectrochemistr. In: Bard AJ Stratmann M (eds.) The Encyclopedia of Electrochemistry. Wiley-VCH Verlag, Weinheim.

7. Oliveira Brett M, Serrano SHP, Piedade JAP (1999) Comprehensive Chemica Kinetics, Applications of Kinetic Modelling. Elsevier, Oxford, UK.

8. Pividori MI, Merkoçi A, Alegret S (2000) Electrochemical genosensor design: immobilisation of oligonucleotides onto transducer surfaces and detection methods. Biosens Bioelectron 15: 291-303.

9. Mascini M, Palchetti I, Marrazza G (2001) DNA electrochemical biosensors Fresenius J Anal Chem 369: 15-22.

10. Palecek E, Fojta M (2001) Detecting DNA Hybridization and Damage. Anal Chem 73: 74 A-83 A.

11. PaneliMG, Voulgaropoulos A (1993) Applications of adsorptive stripping voltammetry in the determination of trace and ultra-trace metals. Electroanalysis 5: 355-373.

12. Kotkar R, Srivastava K (2006) Voltammetric determination of paraaminobenzoic acid using carbon paste electrode modified with macrocyclic compounds. Sensors and Actuators 119: 524-530.

13. Valery HG, Ngono TR, Saâdane H, Ennachete M, Khouili M, et al. (2013) Evaluation of Carbon Paste Electrodes Modified with Organic Molecules for the Analysis of Heavy Metals by Square Wave Voltammetry. Pharmaceut Anal Acta 4: 271.

14. Lauriane NTR, Najih R, Chtaini A (2014) Electrochemical Sensor of Heavy Metals Based on Chelating Compounds. Pharm Analy Acta 5: 4. 